\title{
Work intensification and Ambidexterity - the Notions of Extreme and 'Everyday' Experiences in Emergency Contexts: Surfacing Dynamics in the Ambulance Service
}

\begin{abstract}
Many organizational contexts have experienced radical changes resulting in work intensification. Whilst emergency services face evident 'macro-extreme' challenges (emergencies, major traumas) employees also experience parallel, everyday 'routine' in microsettings. How such micro-episodes interact with macro-extreme dynamics remains underexplored providing an opportunity to extend literature on micro-foundational organizational ambidexterity. This paper empirically examines these dynamics in the UK Ambulance Service by developing a conceptual model to explore the exploitative and explorative shifts and manifestations of work intensification. The findings demonstrate a recognition of macro-type intense-extremes impacts but less appreciation of their interaction with micro-situational mundane-extremes.
\end{abstract}

Key words: Work intensification, Ambulance Services, Extreme, Everyday, Organizational Ambidexterity 


\section{Introduction}

In recent years, the perception and experience of 'extreme' situations have received increasing attention within management literature (Gascoigne et al. 2015, Parry and Buchanan 2015; Lièvre 2016; Turnball and Wass 2015). 'Extremes' are often understood as experiences which point at seemingly uncommon or exceptional occurrences producing intense emotions. These can stem from major events such as, dangerous weather; acts of terrorism; political upheaval; or, war. Hällgren, Rouleau and De Rond (2018) conducted a review of extreme literature and identified categories of: risky, disruption and emergency contexts. The present paper locates in emergency contexts. Importantly, the propensity to associate extremes uniquely with exceptional or major contexts is potentially misleading. By examining extremes through different lenses, it is possible to view the operation of 'extremes' in more everyday and mundane situations rather than viewing them primarily as major events. For instance, introducing 'extreme' in relation to the 'mundane' points at under-explored everyday 'extremes' such as boredom, lack of job enrichment, nervous breakdowns, depression and 'ordinary' stress in quotidian work settings.

Emergency services provide a particularly valuable setting in which to consider the above since they are routinely confronted with extreme incidents interposed with everyday bureaucratic activities however they remain under-researcheda (Wankhade, McCann, and Murphy, 2019). In advanced economy settings, emergency services span many contexts. Emergency services encompass, inter alia: police, ambulance, coastguard, lifeboat, mountain rescue, hospital accident and emergency, and, fire and rescue services. In recent decades, in the United Kingdom (UK), the organization of these services has undergone continual radical transformation driven by political and public policy changes. Given its civic importance, and the transitions taking place therein, emergency services represent an important area for examination corning how 'extreme' situations unfold in relation to everyday contexts. Extant literature on the emergency services has considered a number of prevalent issues and topics including: network structures and command systems (Griffith and Roberts 2015); culture change (Wankhade et al. 2018); performance (Barton \& Beynon 2012); decision-making (Shaw et al. 2013); inter-professional collaboration (Collin et al. 2015); leadership dynamics (Van Wart 2014); and mental health (Wagner et al. 2016). Much of this work has generally concentrated on a functionalistic frame of reference typically focusing on issues of efficiency and effectiveness.

Building on the above important conceptual and empirical developments, the present paper develops a novel over-arching framework of organizational ambidexterity and extremeeveryday work dynamics in 'extreme' contexts empirically considering the ambulance services in a regional setting in the UK (Duncan 1976; Birkinshaw and Gibson 2004; Junni et al. 2013). The paper outlines the possibilities of using this framework as a lens through which to surface and understand the under-explored gap of the inherent extreme-everyday dynamics within these contexts and responds to the following research question:

How do extreme-everyday dynamics operate in individual experiences and organizational ambidextrous settings in emergency ambulance services?

The paper commences with a review of the literature on emergency services and the concept of extremes and everyday work in relation to organizational ambidexterity. A research methodology and case context are outlined and applied which produce subsequent findings and a discussion on the ambidexterity extreme-everyday dynamic and generate contributions and implications. 


\section{Literature review}

\section{Connecting work intensification and extremes with organizational ambidexterity}

Concerns about 'extremes' have become prevalent across a range of domains in recent decades (Granter, McCann and Boyle 2015; Lièvre 2016). Due to shifting dynamics across contemporary social-cultural and geo-political arenas there have been many events in recent decades recognisable as 'extreme' including, for example: military operations (war, peacekeeping); terrorist attacks; political events (UK Brexit vote; Trump's presidential victory); humanitarian crises; and environmental disasters. This characterisation has had a tendency to cast 'extremes' as macro-events and major occurrences. Equally, identifying tropes in the extant literature, Hällgren, Rouleau and De Rond (2018) have signalled the presence of: 'disruption', 'risky' and 'emergency' categories in the extreme literature. Of course, for individuals personally experiencing major 'extremes' such moments are potentially allconsuming of an individual's senses, emotions and lives. This macro-representation of 'extremes' constitutes perhaps the more populist understanding of 'extreme'. However, as major extreme events and contexts seem to become more prevalent in contemporary VUCAprone contexts (volatility, uncertainty, complexity, ambiguity (Cousins, 2018)), it becomes important to broaden the boundaries of 'extreme' events to more everyday routine contexts experienced by individuals (De Certeau 1984; Stokes and Harris 2012). For instance, parallel work has already been conducted on the relationship between individual and organizational resilience (Branicki, Steyer and Sullivan-Taylor, 2016). The ethos of 'extreme' has also been popularised in extreme forms of sports, reality shows, and TV programmes showing 'ordinary/everyday' people doing extreme stunts in the form of 'edgework' - defined by Lyng $(1990,857)$ as: 'activities which involve a clearly observable threat to one's physical or mental well-being or one's sense of an ordered existence.'

Beyond geo-political macro-scale types of extreme events, it can be argued, at a more micro-level, that recent years have witnessed work intensification (Boxall and Macky 2014). This intensification has taken the form of the pursuit of heightened performance through managerialist drives to: work longer and more pressurised schedules; more immediacy in communication response times stemming from the advent of email and social media; and, the rise of globalisation processes which have heightened activity levels (Darics 2014; McDonald and Thompson 2016). In turn, this has often created the impression of extremes occurring within the everyday as opposed to uniquely in macro-extreme contexts. Thus, work intensification has several negative side-effects across organizational settings including stress and illness (Green 2004; McCann et al. 2008; Granter et al. 2019). Importantly, other extreme features have infiltrated 'usual' or everyday lived experience (De Certeau 1984) producing for many a toxic amalgam of banality, bullying, rudeness, marginalisation, gossip, moaning, mundanity and even boredom. These quotidian micro-extremes emerge and operate alongside more episodic (and generally seismic) macro-extremes (for example, major incidents, redundancy, bereavement). Herein, the terms 'micro' and 'macro' identify with the notion of perceived scale of the event or instance. Thus, contemporary work intensification oscillates between these differing extreme events creating a dynamic between major (macro) and local (micro) circumstances. In this way, we introduce and conceptualise that apparently often overlooked mundane-extreme contexts can occur in micro everyday settings. In contrast to mundane-extreme events, we term periodic macro-extreme occasions as intense-extreme events. Here the prefixes 'mundane' and 'intense' are employed to signal a challenge to conventional perceptions in relation to these micro and macro-contexts. By way of illustration, an ambulance driver may have a crisis of confidence, an episode of apparent bullying at work, 
which are personal to him or her (i.e. a mundane-extreme micro-moment). Concurrently, he or she may experience this against the backdrop of a more intense-extreme macro-situation such as a road traffic accident or a major disaster scene - the common perception of extremes in that role but not, in reality, the entire lived experience.

This tension between the mundane-extreme and intense-extreme is potentially likely across many domains of life. However, it is particularly the case in emergency service settings which, because of the sheer physicality of many events of 'extreme' - i.e. attending traumas, accidents - offer striking instances of these mundane-extreme: intense-extreme dynamics. Conceptualising the dynamics of extremes in this way suggests significant and novel insights into the important area of emergency service work with implications for a wide range of organizational issues. Moreover, in relation to various policy changes such as, for example, the introduction of 'interoperability' (i.e. a UK government sponsored cost-saving initiative to promote cross-provision and joint co-ordination between emergency service branches) a deeper understanding of extremes in mundane-extreme: intense-extreme contexts emerges as timely.

Shifts between mundane-extreme and intense-extreme question the capacity for individuals to be able to deal with these dynamics and organizational ambidexterity provides a valuable conceptual framework with which to consider these phenomena (Birkinshaw and Gibson 2004; Junni et al. 2013; Malik, Pereira and Tarba, 2018). Organizational ambidexterity postulates that organizations are frequently confronted by competing dynamic environmental and situational demands taking the form of exploitative and explorative (Malik et al, 2018b; Malik et al, 2017b)). Exploitative points at conditions which exhibit aspects of certainty, existing knowledge and dimensions with known boundaries. Alternatively, explorative states indicate arenas of witness innovation, creativity, uncertainty, complexity and even chaos (Hughes, 2018; Prieto and Pérez Santana, 2012). The dynamics underpinning organizational ambidexterity also play an instrumental role in engendering work intensification as individuals and organizations try to move between routine (exploitative) settings and predictable (explorative) events (Barrutia and Echebarria, 2019; Smith and Evans, 2015). Thus, organizational ambidexterity signals the parallel presence and operation of sometimes complementary yet paradoxical situations (Andriopoulos and Lewis, 2009; Farjoun, 2010). More specifically, structural ambidexterity discusses what types of organizational structure might facilitate an organization and its employees to move between exploitation and exploration (Jansen et al, 2009; Huang and Kim, 2013).Contextual ambidexterity (Raisch et al, 2009) examines attitudes and culture in facilitating readiness to move between exploitative (sic: normal, routine - mundane-extreme) and explorative states (sic: episodic - intenseextreme)(McCarthy and Gordon, 2011; Stokes et al., 2015) - and this has been pointed at in healthcare contexts (Seshadri, Piderit and Giridharadas, 2010; Malik, Boyle, and Mitchell, 2017).

Nevertheless, the ambidexterity literature can appear quite fragmented because the concept of ambidexterity has been used in different research streams providing diverse theoretical underpinnings (Nosella, Cantarello, and Filippini, 2012). For instance, several studies explored the phenomenon of the ambidexterity in the performative and entrepreneurial contexts (Gedajlovic, Cao, and Zhang, 2012; Kammerlander, Burger, Fust, \& Fueglistaller, 2015; Volery, Mueller, \& von Siemens, 2015). In the same vein, Hughes et al (2010) examined the pivotal role of ambidextrous innovation through the hybrid strategy of cost leadership and differentiation in the context of Mexican high-technology ventures. In addition, Campanella et al (2016), exploring the impact of organizational ambidexterity on firm performance, found that banks with high return on equity are characterised by ambidexterity transformative elements of being highly structured and procedural and research intensive.

Nevertheless, Kauppila and Tempelaar (2016), noted that although research on organizational ambidexterity has expanded substantially in the recent years, the determinants 
of individual-level ambidexterity have received less attention. This is curious given the fact that management scholars constantly underscore the importance of investigating both explorative and exploitative activities in individual employees' work roles (Junni et.al 2015). Commenting on this need, Rogan and Mors (2014) proposed that managers' networks are an important yet underresearched factor in their ability to behave ambidextrously by balancing trade-offs between exploring new business and exploiting existing business. Exploring 1,449 internal and external network links of 79 senior managers in a management consulting firm, they showed that there are significant differences in the density, contact heterogeneity, and informality of ties in the networks of individual senior managers engaged in both exploration and exploitation vs. managers that are dealing with either exploratory or exploitative activities (Rogan and Mors, 2014). Moreover, Kapoutsis, Papalexandris, \& Thanos (2016) focused on the role of the individual in the ambidexterity process by presenting the concept of 'influence tactic ambidexterity' to illustrate the frequent use of both soft and hard influences between individuals and its impact on task performance and concluded that political skill positively moderates the relationship between influence tactic ambidexterity and a manager's task performance.

Thus contemporaneously, research on organizational ambidexterity has increasingly focused on micro-foundational aspects i.e. individual-level and group-level behaviours which shape organizational life (Eisenhardt et al., 2010; Felin et al., 2012). Through microfoundational events (sic: mundane-extreme) responses to macro-situational (intense-extremes) and socially-aggregated outcomes occur (Coleman, 1990; Foss and Pedersen, 2016). That is to say, all employees have views regarding how they respond to ambidextrous situations - at various points everyone in the organization has to address one form or another of the ambidexterity problem (Hughes, 2018). Recent work has been conducted on 'front-line' contexts and ambidexterity (Zimmermann, Raisch and Cardinal, 2018) however there is scope to extend this research to wider settings such as emergency services. This overall move towards a more contextual, granular and micro-perspective consideration of ambidexterity is attracting increasing attention (Birkinshaw and Gupta, 2013; Mom, Van den Bosch and Volberda, 2009; Raisch and Birkinshaw, 2008).

Organizations, and individuals therein, have to develop resources and approaches to manage the transitions between states and, on occasion, the simultaneous management of both exploitative and explorative conditions. It can be seen that an exploitative:explorative dialectic readily reflects the overall conditions of micro:macro, extreme:everyday, and, the inherent and resultant mundane-extreme:intense-extreme dynamics. This conceptual framework is mapped out in Table 1 below. By employing organizational ambidexterity as an analytical tool with which to reflect mundane-extreme:intense-extreme dynamics the argument posits the possibility of developing new insights, processes and management approaches with which to understand and manage these environments. Furthermore, from a practitioner perspective, enhanced understanding of the ambidextrous processes in emergency service organizational contexts has the potential to allow better mutual understanding between employees and managers in healthcare contexts (Malik, Boyle and Mitchell (2017a) and it is to an empirical consideration of this context that the paper now turns.

\section{INSERT TABLE 1 HERE}

In the UK context, the emergency services have undergone substantial challenges and transformations in the light of, inter alia: changing demographics; partial privatisation; new public management initiatives; and, post-2008 crisis austerity (National Audit Office NAO 2017; Gurkov and Settles 2011; Knies 2015; Wiesel and Modell 2014). It is acknowledged by the wider public that emergency services personnel are regularly called upon to engage with 
incidents which involve severe, demanding, and even stark scenes and experiences (Granter et al. 2019). The work of the ambulance professionals has been characterised as a dangerous occupation (Maguire et al. 2014) and residing in the extreme and risky category of extremes (Hällgren, Rouleau and De Rond, 2018). In the latest National Health Service (NHS) staff survey, Ambulance Services were: 'far worse than other NHS organisations for discrimination and equal opportunities, illness due to work-related stress and poor employee engagement as compared to other health organisations (Vize 2018; NHS Staff Survey 2018). This situation is exacerbated by a national paramedic shortage and high turnover rates (NAO 2017, 18). Sturges and Guest $(2006,5)$ explored work-life balance in early career recruits and suggested that: 'work/non-work conflict is linked to hours worked, the state of the psychological contract and organisational commitment'. Zhang and Seo (2018), echoing contextual ambidexterity, analysed the social contextual antecedents influencing long working patterns identifying that long working hours were associated with lower job satisfaction and psychological distress. Equally, Piasna (2018) analysing data from the European Working Conditions Survey 20052015 , found evidence of a co-relation between work intensification and long shift patterns, out of hours work and rota patterns imposed by employers. Poor workplace relationships in other healthcare settings, resulting in lower engagement and psychological well-being, have also been recorded (Brunetto et al. 2018, 2016; Kilroy et al. 2016). Thus, a range of issues is evident and the next stage of the argument considers the Ambulance Service in greater detail.

\section{The Ambulance Service: context and background}

UK Ambulance Services constitute a pivotal role in the emergency care system. In England, urgent and support healthcare are provided by ten regional ambulance trusts. In 2015-16, these services cost approximately $£ 2.2$ billion and received 9.4 million emergency calls resulting in 6.6 million face-to-face attendances (NAO 2017, 5). The ongoing Urgent and Emergency Care Review (NHS England 2013) aims to address the fact that Ambulance Services are under intense and unsustainable pressure and, consequently, ambulance crews are adopting new models of care which resolve calls by phone providing advice to callers ('hear and treat'); treating patients at scene ('see and treat') or taking patients to non-hospital destinations (NAO 2017). Ambulance Services have transformed radically in the last decade making significant progress in workforce clinical education and training (College of Paramedics 2015; Pollock 2013; Newton and Hodge 2012). Furthermore, this positive contribution is reflected in various official reports (NAO 2011; Association of Ambulance Chief Executives AACE 2016; NHS England 2013) and academic publications (McCann et al. 2015; Turner et al. 2015; Wankhade and Mackway-Jones 2015). However, a number of challenges continue to hamper the working of these services including: an annual rise of demand for ambulance services of $5.2 \%$ between 2009-16 (NAO 2017); insufficient funding for urgent and emergency activity related to demand (House of Commons 2017); confusion over response time targets with only one trust meeting the three national targets in 2015-16 (NAO 2017, Heath et al. 2018); shortage and retention of paramedic workface (NAO 2017); high sickness absence rates (Wankhade 2016); and, the challenge of working within an increasingly complex health system and developing new skills (Wankhade et al. 2018).

These imperatives point at ongoing significant change and tensions which necessitate responses. In terms of organizational ambidexterity, the Ambulance Services are undergoing transformation exploratively and culturally into a clinically-driven workforce which contrasts with vestigial perceptions of the Service as being fixed in an exploitative manner characterised (even clichéd) as a male-dominant quick response service. Moreover, the Service is moving away from its traditional 'blue collar trade' into a professional workforce (McCann et al., 2013; 
Siriwardena et al. 2010; Snooks et al. 2009). Thus, it finds its environment being reconstructed, and experienced by individuals, in myriad patterns of organizational ambidexterity. The macroand intense-extreme aspects (i.e. attending major trauma and incidents) constitute the primafacie ambidextrous explorative appearance and presentation of the service, in other words, what popular perceptions (including, for instance, television drama series) might bring to mind. However, the transformation of individual and service identity combined with debates over professionalization and structure, point at micro-aspects and a potent role for mundane-extreme experiences at the interface of more exploitative dimensions of organizational ambidexterity. The next stage of the argument considers factors in the Ambulance Service pertaining to the intense-extreme:mundane-extreme dynamic linking these issues to the overall conceptual framework of the argument. In particular, it considers ways in which the dynamic operates, largely unseen by a wider public, across and exploitative-explorative boundaries.

\section{Work intensification and Drivers of the intense-extreme/ mundane-extreme dynamic in the Ambulance Service}

As signalled above, long hours and work intensification are becoming increasingly common in workplaces and Ambulance Services are no exception (Green 2008, 2004; McCann et al. 2008). More widely, Hewitt and Luce (2006) noted that many 'extreme job holders' who were wellpaid and working in excess of 70 hours showed little sense of victimisation or being exploited; rather the workers felt exalted in wearing their commitments as 'badges of honor' (Hewitt and Luce 2006, 52). However, it is also possible to identify jobs in less lucrative and more 'everyday' settings (Lyng 2004; Smith 2004). The discourse on extreme jobs provides an interesting lens with which to understand organizational workings in a wide range of health settings including the Ambulance Service (Gascoigne et al. 2015). Hewitt and Luce (2006, 51) argue that if a person works 60 hours or more in a week and holds a position displaying at least five from nine identified characteristics, it can be termed an 'extreme job'. In the case of Ambulance Services, six dimensions can readily be identified as a regular part of the role: unpredictable flow of work; fast paced work with tight deadlines (pressure of meeting response time targets); 24/7 availability; large amount of travel; mentoring staff (in double-crewed ambulances); and long working hours. Four elements of extremity, namely: responsibility of profit and loss, large number of direct reports, inordinate scope of responsibilities and international travel appear to be less immediately relevant for ambulance workers but nevertheless can be recognised as pressures operant elsewhere in the organization which might intensify pressures for ambulance workers (Alexander and Klein 2001). Thus, by these measures, working within the Ambulance Service constitutes a job with extreme dimensions. The adverse health impact of such 'extreme' conditions has been well-documented (Wankhade 2016; Burke 2009; Coxon et al. 2016; The King's Fund 2015) including the impact on ambulance staff working under emotionally distressing situations in the presence of public and media. Incidents of injury risks, burn-outs, divorce, suicide and drug-abuse are also common for such workers (Maguire et al. 2014; Dembe 2009). Many of the above factors might be readily categorised as originating in micro-situational mundane-extremes in relation, or response, to macro-situational intense-extreme circumstances. In organizational ambidexterity terms, individuals are forced to learn and attempt to respond to the ambidexterity paradox and shift between these micro-macro transitions whilst trying to retaining a sense of everyday wellbeing.

While empirical research has identified a range of drivers which produce extreme experiences, much UK policy focus in the contemporary period (i.e. NHS Five Year Forward View 2014; NHS Confederation 2014) and the Urgent and Emergency Review (NHS England 
2013) generally portrays ambulance work as 'normal' 'hear and treat' at scene rather than the (what might be categorised as the macro-extreme casting) 'scoop and run' (i.e. 'blue light' and sirens rapid transfer of casualties to hospital). This policy debate about the very nature of ambulance work, and how it should normatively be characterised, points directly to the heart of a micro-extreme/macro-extreme ambidextrous dynamic. The over-prioritisation of 'red' calls (8-minute response to life-threatening emergencies) is often cited as one of the main reasons for crew dissatisfaction due to the fact that it tends to be driven by organizational and political reporting imperatives rather than genuine medical necessity (Wankhade 2018; NAO 2017). This 'extreme and normal' duality has been overlooked in the literature as the emphasis has rather tended to be primarily on ambulance professionalization and work intensification (Granter et al. 2019; McCann et al. 2015) or ambulance culture (Wankhade et al. 2018; Wankhade et al. 2015).

Moreover, Institutional drivers play a role in creating such roles ( $\mathrm{Ng}$ and Feldman 2008; Scott 2008; Feldman, 2002). At the macro-level, the growing competitive pressures, often driven by technological advances and 24/7 connectivity, have further impacted on managerial expectation leading to work intensification (Prichard et al. 2014; Turnbull and Wass 2015). The 'management by targets' approach adopted after the introduction of the New Public Management (NPM) ideology into the UK NHS has also contributed to additional pressures on the workforce (Pollitt 2003). The limitations of the ambulance response-time target regime, including impact on workforce patterns and the various unintended consequences, have been well-documented (Heath and Wankhade 2014; Wankhade 2011). Failure to achieve targets and poor performance scores in a linear manner are often viewed as a personal failure by senior NHS leaders resulting in a climate of mistrust and conflict and engendering a range of microextreme situations (Gieske et al. 2019; Wankhade and Brinkman 2014).

Occupational drivers, highlighting the nature of professional and managerial work in different settings provide further supporting evidence into extreme jobs contexts. Specific characteristics of work determining long and intense work hours has been summarised by Gascoigne et al. (2015) and ethnographic studies in Ambulance Services (Tangherlini 2000; Reynolds 2009, 2010) and police (Charman 2013) highlight these issues. In relation to this overall context, the changing nature of emergency demand provides some insights. While, there is an average annual increase of five percent in demand for Ambulance Services, only 10 percent of callers dialling 999 actually have life-threatening emergencies (Evans et al. 2014). Moreover, 77 percent of emergency calls resulting in ambulance journeys to hospital lead to admission in forty percent of cases while 50 percent of these could be treated at the scene or in the community (Turner et al. 2015). Linked to this, much of the success of the ambulance services towards becoming a 'normalised' profession depends on ambulance workers taking on a clinically enhanced role (with greater risks). Extant evidence concerning safety, effectiveness and funds to support these changes is currently insufficient (O'Mara et al. 2015; Fisher et al. 2015; Turner et al. 2015).

The above macro-drivers impact at the micro-level. The Boorman Review (2009) looking into the health and well-being of NHS staff recommended that NHS staff health and well-being needs should be central to the NHS and as vital at board level as much as at ward level (DH 2009). The high levels of mental and health-related issues identified within ambulance workers underpin high sickness rates. Thus, the emotional challenges of the job are well-recognised but not always adequately understood or addressed. Lack of organizational support for staff dealing with sickness matters is also an issue (Wankhade 2016). One known cause has been the way ambulance trusts deploy individuals in solo-responder cars (Rapid Response Vehicles or RRVs) essentially to meet the key response time targets (House of Commons 2017; NAO 2017; Wankhade 2011), often creating isolation and barriers to support and communication. 
Furthermore, the growing number of instances pertaining to discrimination is creating further tensions for ambulance services. The King's Fund (2015) investigated reports of discrimination amongst NHS staff (including ambulance trusts) using NSS Staff Survey returns of 2014 and reported levels of discrimination as highest amongst ambulance workers. More generally, cases of bullying and harassment of ambulance staff are also on the rise (CQC 2016) and now covered in the media (Morri 2017). Therefore, NHS institutional and occupational macro-drivers create particular mundane-extreme tensions, playing out in a localised and micro-manner. The above examination of the factors operating in the Ambulance Service context, imply a 'disconnect' between macro-policies and the micro-impacts in a number of mundane-extreme situations. This current lack of understanding and insight has serious implications for the successful development of the ambulance services and the next stage of the argument empirically explores this tension in the field.

\section{Methodological approach}

The study adopts a qualitative approach (Silverman 2011) and the main collection of the field research data was undertaken by the first named author during 2008-09 in a large NHS ambulance service located in the UK. Adopting a case context approach (following Flick 2009; Yin 2009), the researchers were mindful of drawing on data from specific and particular contextual case-like settings. Mindful of the time-period covering the data, the research team continued to follow closely latest developments in the sector which confirmed that while the Ambulance Service context continues to experience change reflective of organizational ambidextrous dynamics, unfortunately, it is apparent that the experience of the ambulance operatives continues contemporaneously to be challenging and is far from resolved. Thus, embracing an exploratory framework embedded in a rich case-based approach presented the opportunity to explore and examine the experiences of a range of organisational actors within the context of their own social settings. Such an approach is also supported in the literature (Watson 2011; McCann et al. 2015; Yin 2009). Responding to Junni's et al. (2013) call for more qualitative studies in organizational ambidexterity the research adopted an interpretive approach within an organizational ambidexterous framework, employing semi-structured interviews and non-participant observation. Ethics approval for the larger study was obtained from the local NHS research ethics committee. The in-depth interview sample for this study included 14 participants (see Table 2) with a range of interviewees engaged at various levels/job descriptions in the ambulance services (Maylor and Blackmon 2005).

\section{INSERT TABLE 2 HERE}

A purposive sampling technique was used to recruit participants to the study and was considered most appropriate since we were interested to explore the response of different actors to the macro-micro extreme-normal dynamics in the chosen organisation (Miles and Huberman 1994; Denzin and Lincoln 2011). Semi-structured interviews typically lasted between 30-60 minutes and were audio recorded with prior consent for subsequent transcription. The interviewees included: senior board executives, corporate, area and field managers and frontline paramedics across the trust. The chosen sample allowed a better understanding of the dynamics and interactions between these different occupational groups.

An additional 20 hours of non-participant observation was also done in the study. This included sitting at three executive and two managerial meetings (15 hours) and accompanying ambulance crews at the stations and back of ambulances over three visits (5 hours). These 
activities included: observation of the weekly board executive meetings; attendance at the middle executives and managerial meetings; and travelling at the back of an ambulance with crews including observations at the ambulance stations and in canteens. Informal 'corridor' chats with staff further complemented the observation. Prior consent for such non-participant observation was obtained from the trust and the personnel observed. The aim for such observation was to further assist our understanding of an ambulance trust and watch these actors in their social settings amidst their daily routines which further helped our conceptualisation of the extreme-normal dynamics. Use of observational method is also becoming popular in other recent studies in the emergency services (Granter et al. 2019; Charman 2017; McCann et al. 2013). We recorded the observation data manually within the first few days and used an informal coding framework to aid our interpretations to the events being observed.

Discussion between the authors helped to refine our arguments. Data presented in the Findings section are derived both from the interviews and our observation and is suitably signposted. The semi-structured approach and naturalistic data collection afforded respondents the opportunity to represent their experiences in relation to the situations experienced. The data were analysed using Template Analysis (King 2004) which allowed a range of themes related to 'extremes' to be identified (Gray 2009; King and Horrocks 2010). This method assisted in identifying important themes and sub-themes and facilitated the process of gaining rich insights from the contextual data. Emerging themes were repeatedly examined by the research team to draw out relationship between various codes. The data features pointed at ambidextrous-style traits (e.g. stability, uncertainty and so forth) which allowed the subsequent conceptual design of the research in the light of the evolving nature of organizational ambidexterity literature. This inductive approach helped us to explore situational dynamics of our case and allowed rich insights into behaviours of the actors (Gioia et al. 2013; Langley et al. 2013).

There are some limitations to this study. Data are gathered from one (albeit large) NHS ambulance trust in England with a relatively small sample and was collected during 2008-09. The paper engages contemporary policy documents (such as NAO 2017; House of Commons 2017) cited in the previous section and notes these in relation to the data-collection period. We argue that the evidence presented in this paper still corresponds to arguments examining the situations which - while not expressly employ the terminology - point at dynamics of extremenormal situations and notions of work intensity in the ambulance service in recent academic studies (see Granter et al. 2019; Wankhade 2018; Heath et al. 2018) including the policy documents. The present paper, and the data developed therein, was able to identify and code traits resonant with forms of extreme and reflective of exploitative and explorative contexts. Furthermore, our argument is that the context of the ambulance service operations and delivery has (unfortunately) revolved around a set of recurrent and repetitive issues over the last decade. The challenges surrounding the perverse consequences of ambulance performance targets highlighted in subsequent studies by Wankhade (2011), the role of sub-cultures (Wankhade 2012), and professionalization of the workforce (McCann et al. 2013), still resonate in cited recent academic studies and policy documents mentioned above. The data relied upon for our analysis is therefore still relevant to explore the dynamics of the ambidextrous situations of extreme-normal situations.

\section{Findings}

The data analysis generated a number of themes in relation to the mundane-extreme and the intense-extreme conceptual framework developed in the preceding discussion, mediated by the 
work intensification observed and centred on: Schisms isolation and alienation; work intensification; lived experience of intense-extremes; and, performance and extremes.

\title{
Schisms - isolation and alienation as mundane-extremes
}

It was apparent that the Ambulance Service was viewed as the poor cousin of NHS partners. The notion of interoperability with other emergency services was seen as weak. Part of the mundane-extremes seemed to arise from legacy issues juxtaposed against drives for modernisation. This centred on whether the Ambulance Service and its personnel were perceived as an arm of the 'blue light' (i.e. emergency services) or, alternatively, a health arm of the NHS?

\begin{abstract}
'I think the bigger problem we have had is that as an ambulance service we have been stuck in the middle between emergency services and the NHS and 10 years ago we were very much part of the emergency services. We were structured on that format and that's how everyone saw us. '(Senior ambulance executive I)
\end{abstract}

Part of the schism arose from a conflicting understanding of the Ambulance Service's role. Some respondents reported that they were perceived as a 'scoop and run service' where they were seen primarily as a unit which picked up patients and transported them. In this regard, the 'transporting' construction of Ambulance Service persona is reflected in issues of ambidexterity. On the one hand, the 'scoop and run' identity echoes a blue-collar, manual labour role echoing exploitative fixed, boundary-limited and rather 'known' and predictable dimensions of a circumscribed view of the Ambulance Service. For many respondents, this created tensions because it negated possible alternative experience of the Ambulance Service as a clinical arm comparable to other health services. This represented a form of mundaneextreme which eroded morale in a chronic rather than an acute manner.

'The biggest problem, issue, challenge, whatever you call it that's facing us is actually the fundamental culture that underpins everything in the organisation at both manager and staff level which is one of the blue collars to professionalism.' (Observational data).

In contrast, the possibility of cultivating an 'emergency service worker' role presented more explorative dimensions. This pointed at an Ambulance Service role where it was seen as a self-aware, developing and evolving professional role comparable to other health professional colleagues. Herein, the role suggested expansive, newly evolving and even unforeseen dimensions.

'We need to change it into a culture where they (paramedics) can think, where they can assess, where they can decide not just against algorithms but actually against the scope of practice. That is a significant migration not only in individuals, but also in systems.' (Senior ambulance executive II)

The underlying tensions informing this view were reported as often being fuelled by cultural representations on televisual and film dramas. Such dramas were reported as presenting Ambulance Service personnel as being 'high octane' adrenalin junkies on the one hand or dependable routinely plodding carers on the other. Most respondents felt that popular television 
show representations did little to show that clinical evidence behind driving fast and saving patient lives was actually statistically insignificant.

'A lot of our staff don't think going to patients with minor things and leaving them at home is a worthwhile thing to have done...It's like the telly isn't it? (Senior ambulance executive III)

\section{Consequences of work intensification: transitions between mundane-extremes and intense- extremes}

Ambulance Service respondents reported that a key source of work intensification was the prescribed 8-minute target for response to calls. They felt that the target was simplistic and over-shadowed their role feeding into, for example, televisual stereotypes of paramedic life.

'I am sure you've heard it before that as an ambulance service if you get to a patient in 8 minutes but they die, we succeed, if we get there in 9 minutes and the patient survives, we fail". I mean that is just crazy' (Observational Data).

It was evident that such mechanistic dimensions informed the realities involved in paramedic experience. It could be argued that the target created a form of concrete, yet unrealistic, exploitative atmosphere and reality around this part of the Ambulance Service role.

'The trouble is that we get a 'Hawthorne Effect' if you like around targets. So if you are delivering $85 \%$ against the $75 \%$ target you will quickly find your finances reigned in such that you can achieve $75.02 \%$. That's the problem with targets.' (Senior operation manager I)

'Performance to me doesn't point to facts and figures. Performance to me means with the skills I have as a paramedic, how I can make their condition better. '(Senior paramedic I)

The circumscribing of purported boundaries and certainties around the role, and its operation, exhibited exploitative dimensions. Many respondents believed the eight-minute target was more of a 'social' or public relations target rather than an absolute. Respondents felt it would be better if they acknowledged and respected the explorative unpredictable, variable and ever-changing dynamics of the situations against which it was conducted. The overall, situation in relation to the 8-minute response time was seen as being made more intense and complex because of a general lack of awareness among the public that there are alternatives to dialling 999 (i.e.111). Even when members of the public were aware of alternatives they often reported that they were not as credible as 999.

'Certain patients can abuse the system and they learn what gets them an ambulance quickly. You do get the regulars who ring up. Then people see things on TV about calling 999. Definitely abuse goes on.' (Senior Station Manager I, Observation Data)

Due to work intensification, sickness levels in the Ambulance Service were reported as very high but underlying causes and dynamics appeared less immediately addressed by the Ambulance Service. 


\section{Lived Experience of Intense-Extremes}

Even though much of the role of paramedic life is played out through mundane-extreme organizational everyday experiences, inevitably in a job role such as those on the front-line of the Ambulance Service, moments occurred which clearly resided in the intense-extreme domain. For example, recent terrorist incidents have exposed the ambulance crews to the physical pain of death and trauma. A number of comments and responses were made in relation to these aspects of the role.

'This job has a different type of stress. When I get there because I'm a lone worker, there's an additional stress...I've become quite numb to it, quite resistant to any sort of emotional impact that the job clearly has had on me in the past because I have cried on jobs before today, and at home as well.' (Senior paramedic II)

'I don't really know how I deal with them in those terms. Probably since I've come into this job I would say my consumption of alcohol has been a lot greater than before I actually came into the job. '(paramedic III)

Also revealing here is the use of alcohol as a coping mechanism to address intenseextreme experiences. However, this does not of course preclude the possibility of such coping mechanisms also being applied to mundane extremes. In relation to intense-extremes the important idea of a gradual numbing of the senses was reported. Another interesting aspect of such lived experiences was the 'physical intensity' of the job and how it impacted staff.

'There are lots of people who have been on ambulance and are on shift grind. But there are lot of de-motivated staff who get the same jobs over and over again and were sick of getting to do the same things. It was not particularly challenging.' (Senior operations manager I)

'My challenge in the work is getting the right leisure, rest, work, education, but when I'm in work the immediate challenges can be quite simply just getting through the job because it can be so frustrating when you're on the road for 12 hours and you're driving.' (Senior paramedic II)

Several respondents also expressed their frustration in delivering a cultural change with such a heavy workload, which also depended on interactions with the rest of the health economy and also how much the ambulance service can persuade the wider NHS to invest in them at the speed necessary in order to deliver the change.

II think that there's a need to change the nature of the workforce and I'm not sure you change the nature of the workforce by giving them the 5 days a year to train'. (Station Manager II)

Some respondents also moaned about the additional challenge of 'educating' other partners in the wide health economy.

'We need to improve commissioning understanding of ambulance service rather than being told that you got to improve your performance when they got absolutely no idea of what we are doing. We have to take some blame ourselves 
These quotes highlighted some failure on part of senior leadership to positively engage with staff and managers on organisational goals and objectives. The need for adequate training and support to staff in mitigating some of these negative perceptions and influences of organisational exigencies couldn't be stressed enough.

\section{Performance and Extremes}

Many respondents commented on the role of performance targets in creating varying tensions in their work lives. There was a sense that the targets were unrealistic and did not reflect their lived experience (Knights and Willmott 1999). This generated form of mundane-extreme atmosphere, which pervaded much of the respondent feedback which individual report tensions and affected morale levels:

'As part of a set of performance indicators I would agree it has its part to play but to focus everything on achieving an 8-minute hit is completely tosh quite frankly. What the hell difference does it make? It's only relevant when compared to the outcome.' (Ambulance clinician)

Interestingly, when Ambulance staff discussed targets, this was construed negatively, intensifying mundane-extreme feelings:

"I think that's something we have to overcome in the mind-set. If you talk to managers about performance management their automatic assumption is that is a negative reflection on why haven't you achieved $X, Y$ and $Z$, as opposed to a positive reflection of how to do things better. And it's going to be an interesting culture challenge I suspect for the ambulance service over the next few years. (Senior ambulance executive IV)

Many respondents questioned the rationale (both in medical and logistical terms) underpinning the setting of a need to respond and arrive at calls within 8-minutes. The act of travelling at high speed to a call with sirens and flashing lights on was a clear instance of intense-extreme for respondents, but one often felt to be not useful and misplaced:

'There are hundreds if not thousands of occasions when you arrive within eight minutes to a supposed 'red' response but it was never a red response in the first place because the nature of the other person telling the other person on the phone and they put it into the computer with the code for such response.'(Operations Manager II)

There was an interesting timeline and dynamic in relation to seeing the rapid response calls in differing ways:

'If you have a student who's come from a different job whilst they'll be in love with the fantasy of the blue lights, that'll soon be driven out of them by the incessancy of the job- where people did really benefit from a paramedic practising his skills, where the patient did really benefit from having an ambulance.' (Senior ambulance executive $V$ ) 
Our observations and informal discussions with staff confirmed such concerns about the primacy of the targets as the key performance indicator for the service. It was argued that response time targets were quite 'divisive' and were largely conceived at a time when ambulance crews had a very linear process in emergency services, requiring them to get to patients very quickly and then transport them to the hospitals. With development of the clinical skills agenda, the relevance of the response time targets as a measurable organizational performance has to be less significant since it only reflects one element of care provided by the organisation.

'Good performance should be holistic in its approach in that it looks at the contribution of all elements of the organization that are critical to its success so that it isn't focused purely on or directed only on one element.' (Senior station manager III)

The paper has now developed a range of findings and the argument now progresses to discussion.

\section{Discussion}

The findings, in conjunction with the analysis of the literature and theoretical framework development, highlight how the predominant prima facie focus on, what has herein been couched as intense-extremes, has been privileged over mundane-extremes by senior management, policymakers and indeed in wider public perception. Thus, attention is focused on the 'macro-extremes' (such as eight-minute targets) with little or no attention being accorded to micro and mundane-extreme events (such as health, wellbeing) in the course of front-line and daily life (Zimmermann, Raisch and Cardinal, 2018). Nevertheless, consequences of individuals trying to manage the ambidextrous dialectic between the mundane and the extreme has major consequences as evidenced in the rise in, for example, reported illhealth and stress (Stokes et al. 2015; Wankhade 2016). Ambulance performance regimes have been criticised as a perfect example of: 'hitting the target and missing the point' (NAO 2017; House of Commons 2017) with a growing recognition that the current response-time standards have become dysfunctional (Heath et al. 2018). Such mis-alignments between individual and organization (Hallgren et al., 2018) are characteristic of the schisms, isolation and alienation which are created in trying to manage ambidexterity and tensions between mundane-extremes and intense-extremes. While, indeed, a new Ambulance Response Programme (ARP) trial is currently underway which will potentially allow better utilisation of resources (Keogh 2017) and to refocus the service on the 'outcome for patients' rather than the clock there is poor confidence that this will bridge the issues pointed up by the inherent intense-extreme: mundane-extreme dynamic.

In relation to organizational ambidexterity it was interesting to observe how respondent roles appeared to oscillate and transform across exploitative/mundane-extreme and explorative/intense-extreme domains. Alternatively, the exploitative view cast ambulance workers primarily as 'blue collar' staff mainly in a 'transport' role juxtaposing with a perception often projected by others of ambulance staff as dynamic, fast moving medical practitioners in a constant explorative mode (Granter et al. 2019; Wankhade et al. 2018). One of the key underlying features in the data concerned the language used and weariness of tone employed by respondents. It seemed that a 'fatigue' was induced by the persistent mundaneextreme, exploitative-explorative shifting contexts, sapping energy to deliver 'performance' crossing ambidexterity boundaries from mundane-extreme moments to deal with intense- 
extreme moments. In an explorative extreme manner these dynamics created a challenge for the organization resulting in high sickness rates (Wankhade 2016). Moreover, this pointed at the need to note and address the insidious encroachment of normalisation of mundane-extreme moments and atmospheres. Indeed, there was some evidence that respondents were using 'sickies' (absence through sickness leave) as an individual creative explorative strategy with which to manage the exploitative organizational mechanistic policy and managerialisticinduced macro-extremes - the intense-extreme moment of eight-minute emergency calls was widely cited in this regard. Dissatisfaction with work intensification issues also pointed at the changing scope of paramedic practice in, for example, university-led education \& new specialised roles (Boxall and Macky 2014). These explorative options and possibilities tended to lead to more frustration, resignations and out-of-ambulance-trust employment opportunities such as GP surgeries, out-of-care facilities. As a further observation, it can be seen how employees at different points of their career had varying attitudes to intense-extreme and mundane-extreme perceptions of urgent calls. For the young or early career recruit intenseextremes were seen as exciting however very quickly the intense-extreme was galvanised into a mundane-extreme by the sheer unrelenting demands placed on the service. This pointed at a generational issue that is operating with the exploitative-explorative dynamics of the Ambulance Service Context.

There appears a need for the Ambulance Service to focus on the importance of a more every day, lived experience (De Certeau 1984; Knights and Willmott 1999) understanding of the Service's work and experience. This comes with recognition that, in many ways, ambulance workers experience a range of 'extremes in the everyday' (mundane-extremes), which often operate in parallel with more profiled macro and intense-extreme events. This acknowledgement is not yet fully developed in the Service and there appears, what might even be termed, an exploitative operative stance in contestation with a more explorative managerial response as these upper echelons seek to respond to the highly overall explorative context of the NHS. The findings also underline the prevalence of extreme-everyday tensions signalled in the above argument, which have clear ramifications from a practitioner perspective. Serious concerns about low staff morale due to 'workload pressures' (Chatzitheochari et al. 2009; Haplern et al. 2011) are supported in the present study. Sickness absence rates, which are among the highest in the Ambulance Services, are contributing further to the worsening shortage and retention of paramedic workforce (NAO 2017, 10). These may allude to sustained pressures to meet the performance demand but there is also a need to examine underlying causes and factors (NHS 2018; Mishra et al. 2010).

There is a clear need to understand how usage is changing - and to support staff to respond to new challenges. Central to such a response is the need for senior managers, policy makers, and indeed Ambulance Service crews themselves, to better understand how to manage the potent tensions, which are occurring across the exploitative/ mundane-extreme and explorative intense-extreme boundary. It can be argued that the pressures presented by unseen or ignored transitions across the ambidextrous divide actually necessitate the reinforcement of skills, processes and mechanisms at individual, team and organizational levels. Such responses need to find ways in which the schisms (blue-collar transitions to professional para-medic, office politics to catastrophic road traffic accident) might be ameliorated or even overcome. For example, mentoring, coaching or similar approaches in conjunction with a less forceful top-down explorative managerial approach may go some way towards developing a constructive response (echoing Branicki, Steyer and Sullivan-Taylor's (2016) call in relation to individual-organizational dynamics and resilience).

In summary, the paper and its findings have highlighted the manner in which extremes can be identified and located in what appear prima facie seemingly mundane and everyday contexts and their relevance for both academic and practitioner communities. The lack of 
recognition and acknowledgement of this issue-herein portrayed and represented through a framework of organizational ambidexterity-points at serious underlying issues, which may provide explanations and greater understanding for many of the problems currently being experienced in the Ambulance Service in the UK. There are a few limitations of our study. Data generation took place only in the UK in a set period. This means that the respondents were employees of a particular area and organization (i.e. Trust) within the NHS and this means that a particular set of cultural and contextual factors may be at play. Nevertheless, future research may well replicate and amplify the findings in relation to wider areas and (national) contexts.

Several policy and practice implications can emerge from our study. The relationship of the mundane-extreme to the intense-extreme (linked for example to high sickness levels and ambulance work patterns) should receive greater management and policy attention than at present. Empirical studies in different national settings exploring the impact of extreme and normal dichotomy on health and well-being (Schor 2011; Gascoigne et al. 2015; Athota and Malik, 2019) can provide a fruitful research agenda. Moreover, there are indications that generational or length of service issues may well be a factor in emergent tensions in the Ambulance Service.

\section{Conclusions}

Within this paper, we have developed a conceptual approach which illustrates the underlying dynamics in the tension between 'extremes' in macro contexts (e.g. linked to major incidents) and micro-extremes experiences in localised, individually focused settings, using the underresearched context of the UK Ambulance Service as our site of empirical examination. We have developed an innovative framework of organizational ambidexterity with which to consider how individuals are subjected to rapid transitions between everyday 'mundaneextreme' and 'intense-extreme' and cope with the pressures this creates.

Overall, the paper found that while policy and managerial actions attempt to construct the role in a particular manner, many of these actions, also create challenges and problems by occluding mundane-extreme issues and indeed may even invoke them through rapid changes in activity modes, harassment, bullying and legacy issues in the nature of the role. The inability to understand the nature and range of work intensity dimensions and address, the intenseextreme/mundane-extreme dynamic within the context of environmental organizational ambidexterity in the NHS and the Ambulance Service has important consequences for macroissues of performance not only within this organizational context but potentially across more diverse and varied organizational spaces.

\section{References}

Association of Ambulance Chief Executives AACE. 2016. Annual Report, 2015-2016; London: AACE.

Athota, V. S., and Malik, A. (2019). Managing Employee Well-being and Resilience for Innovation: Evidence from Knowledge-intensive Service Industries. Switzerland: Springer Nature Switzerland AG.

Acker, J. 1990. "Hierarchies, Jobs Bodies: A Theory of Gendered Organizations". Gender Society 4(2): 139-158. 
Barton, H., and M. Beynon. 2012. "Policing for the people: A cluster based investigation of the relationship between police force operational performance and public opinion." International Journal of Emergency Services, 1(1): 29-38.

Barrutia, J.M., and C. Echebarria. 2019. "Drivers of exploitative and explorative innovation in a collaborative public-sector context”. Public Management Review 21 (3): 446-472.

Birkinshaw, J., \& Gupta, K. (2013). Clarifying the distinctive contribution of ambidexterity to the field of organization studies. Academy of Management Perspectives, 27(4), 287-298.

Birkinshaw, J., and C. Gibson. 2004. "Building ambidexterity into an organization". Sloan Management Review 4: 47-55.

Boorman, S. 2009. NHS Health and Well-being Review: Interim and Final Report, London: Department of Health.

Boxall, P., and K. Macky. 2014. "High-involvement work processes, work intensification and employee well-being”. Work, Employment \& Society 28(6): 963-984.

Branicki, L., Steyer, V., \& Sullivan-Taylor, B. (2016). Why resilience managers aren't resilient, and what human resource management can do about it. The Journal of Human Resource Management, 1-26.

Brunetto, Y., M. Xerri., E. Trinchero., R. Beattie., K. Shacklock., R. Farr-Wharton., and E. Borgonovi. 2018. "Comparing the impact of management on public and private sector nurses in the UK, Italy, and Australia". Public Management Review 20 (4): 525-544.

Brunetto, Y., M. Xerri., E. Trinchero., R. Farr-Wharton., K. Shacklock., and E. Borgonovi. 2016. 'Public-Private Sector Comparisons of Nurses' Work Harassment Using Set: Italy and Australia". Public Management Review 18 (10): 1479-1503.

Buchanan, D.A., E. Parry, C. Gascoigne, C. and C. Moore. 2013. "Are healthcare middle management jobs extreme jobs?” Journal of Health Organization and Management 27

(5): 646-664.

Burke, R.J. (2009) Working to Live or Living to Work: Should Individuals and Organizations Care? Journal of Business Ethics, 84 pp167-172.

Burke, R. J. and L. Fiksenbaum. 2009. "Are managerial women in "extreme jobs" disadvantaged?" Gender in Management: An International Journal 24(1): 5-13.

Campanella, F., Del Giudice, M., Thrassou, A., \& Vrontis, D. (2016). Ambidextrous organizations in the banking sector: an empirical verification of banks' performance and conceptual development. The International Journal of Human Resource Management, 131.

Care Quality Commission CQC. 2016. South East Coast Ambulance Service NHS Foundation Trust Quality Report, London: CQC.

Carter, L. 2016. Operational Productivity and Performance in English NHS Acute Hospitals: Unwarranted Variations: An Independent Report for the Department of Health by Lord Carter of Coles London: Stationery Office.

Chatzitheochari, S. and S. Arber. 2009. "Lack of sleep, work and long hours culture: evidence from the UK Time Use Survey". Work, Employment \& Society 23(1): 30-48.

Charman, S. 2013. "Sharing a laugh: the role of humour in relationships between police officers and ambulance staff". International Journal of Sociology and Social Policy 33 (3/4): 152166.

Collin, K., S. Herranen, U. Valleala, and S. Paloniemi. 2015. "Interprofessional collaboration during an emergency ward's rounds." International Journal of Emergency Services, 4(2): $212-226$.

College of Paramedics. 2015. Paramedic Curriculum Guidance, 3rd ed., Derby: The College of Paramedics.

Coxon, A., M. Cropley, P. Schofield, K. Start, C. Horsfiled, and T. Quinn. 2016. "You're never making just one decision': exploring the lived experience of ambulance emergency 
operations centre personnel". Emergency Medicine Journal, March, doi: 10.1136/emermed2015-204841.

Cousins, B. (2018). Design Thinking: Organizational Learning in VUCA Environments. Academy of Strategic Management Journal, 17(2).

Darics, E. 2014. "The Blurring Boundaries Between Synchronicity and Asynchronicity New Communicative Situations in Work-Related Instant Messaging". International Journal of Business Communication 51(4): 337-358.

De Certeau, M. 1984. The Practice of Everyday Life, Berkeley: University of California Press.

Dembe, A.E. 2009. "Ethical Issues Relating to the Health Effects of Long Working Hours". Journal of Business Ethics 84 : 195-208.

Duncan, R. B. 1976. "The ambidextrous organization: Designing dual structures for innovation" In The Management of Organization, edited by Kilmann, R.H., L. R. Pondy, and D. Slevin, 167-188. New York: North-Holl.

Eisenhardt, K. M., Furr, N. R., \& Bingham, C. B. (2010). CROSSROADS-Microfoundations of performance: Balancing efficiency and flexibility in dynamic environments. Organization science, 21(6), 1263-1273.

Evans, R., R. McGovern, J. Birch, and D. Newbury-Birch, D. 2014. "Which extended paramedic skills are making an impact in emergency care and can be related to the UK paramedic system? A systematic review of the literature." Emergency Medicine Journal 31: 594-603.

Feldman, D. C. 2002. 'Managers' propensity to work longer hours A multilevel analysis'. Human Resource Management Review 1293): 339-357.

Felin, T., Foss, N. J., Heimeriks, K. H., \& Madsen, T. L. (2012). Microfoundations of routines and capabilities: Individuals, processes, and structure. Journal of Management Studies, 49(8), 1351-1374.

Fisher, J.D., K. Freeman, A. Clarke, et al. 2015. "Patient safety in ambulance services: a scoping review". Health Service and Delivery Research. 3(21). Available at http://dx.doi.org/10.3310/hsdr03210.

Flick, U. 2009. An introduction to qualitative research ( $4^{\text {th }}$ ed.). London: Sage.

Gascoigne, C., E. Parry, and D. Buchanan. 2015. "Extreme work, gendered work? How extreme jobs and the discourse of 'personal choice' perpetuate gender inequality". Organization. 22(4): 457-475.

Gedajlovic, E., Cao, Q., \& Zhang, H. (2012). Corporate shareholdings and organizational ambidexterity in high-tech SMEs: Evidence from a transitional economy. Journal of Business Venturing, 27(6), 652-665.

Gieske, H., B. George, I. van Meerkerk, and A. van Buuren. 2019 "Innovating and optimizing in public organizations: does more become less?" Public Management Review. DOI: 10.1080/14719037.2019.1588356.

Granter, E., P. Wankhade, L. McCann, J. Hassard, and P. Hyde. 2019. "Multiple Dimensions of Work Intensity: Ambulance Work as Edgework". Work Employment and Society 33(2): 280-297.

Granter, E. J., L. McCann, and M. Boyle. 2015. "Extreme Work / Normal Work: Intensification, storytelling and hypermediation in the (re)construction of 'the new normal"." Organization,22(4): 443-456.

Gioia, D. A., K.G. Corley, and A.L. Hamilton. 2013. "Seeking qualitative rigor in inductive research: Notes on the Gioia methodology". Organizational Research Methods 16(1): 1531.

Gray, D. E. 2009. Doing research in the real world (2nd ed.). London: Sage.

Green, F. (2001). It's been a hard day's night: the concentration and intensification of work in late twentieth-century Britain. British Journal of Industrial Relations, 39(1), 53-80. 
Green, F. 2004. “Why has work effort become more intense?” Industrial Relations 43(4): 709741.

Green, F. 2008. "Work effort and worker well-being in the age of affluence" In The long work hours culture: causes, consequences and choices, edited by R. J. Burke, and C. L. Cooper. 115-126. Bingley:Emerald.

Griffith, J. C., and D.L. Roberts. 2015. "A meta-analysis of crew resource management/incident command systems implementation studies in the fire and emergency services". Journal of Aviation/Aerospace Education \& Research 25(1): 1-25.

Gurkov, I., and A. Settles. (2011. "Managing organizational stretch to overcome the uncertainty of the Great Recession of 2008". International Journal of Organizational Analysis 19(4): 317-330.

Halter, M., S. Vernon, H. Snooks, A. Porter, J. Close, F. Moore, and S. Porsz. 2010. "Complexity of the decision-making process of ambulance staff for assessment and referral of older people who have fallen: a qualitative study." Emergency Medicine Journal 28: 44-45.

Hällgren, M., Rouleau, L., \& De Rond, M. (2018). A matter of life or death: How extreme context research matters for management and organization studies. Academy of Management Annals, 12(1), 111-153.

Heath, G., J. Radcliffe, and P. Wankhade. 2018. "Performance Management in the Public Sector: The Case of the English Ambulance Service." In The Routledge Companion to Performance Management and Control, edited by E. Harris, 417-438. London: Routledge.

Heath, G., and R. Radcliffe. 2010. "Exploring the utility of current performance measures for changing roles and practices of ambulance paramedics." Public Money \& Management 30(3): 151-158.

Heath, G. and P. Wankhade. 2014. "A Balanced Judgement?: Performance Indicators, Quality and the English Ambulance Service; some issues, developments and a research agenda." The Journal of Finance and Management in Public Services 13 (1): 1-18.

Haplern, J., R.G. Maunder, B. Schwartz, and M. Gurevich. 2011. "Identifying risk of emotional sequelae after critical incidents." Emergency Medicine Journal 28(1): 51-56.

Hewitt, S.A., and C.B. Luce. 2006. "Extreme Jobs: The Dangerous Allure of the 70-Hour Work week." Harvard Business Review 84 (12): 49-59.

Hegg-Deloye, S., P. Brassard, N. Jauvin, et al. 2014. "Current state of knowledge of posttraumatic stress, sleeping problems, obesity and cardiovascular disease in paramedics". Emergency Medicine Journal 31: 242-247.

Hignett, S.M. 2015. "Musculoskeletal injury risks for ambulance workers". Journal of Paramedic Practice 7(6): 226-227.

House of Commons Committee of Public Accounts. (2017. NHS ambulance services. Sixtysecond Report of Session 2016-17. London: Stationery Office.

Hughes, M., Martin, S. L., Morgan, R. E., \& Robson, M. J. (2010). Realizing product-market advantage in high-technology international new ventures: The mediating role of ambidextrous innovation. Journal of International Marketing, 1-21.

Jansen, J. J., Tempelaar, M. P., Van den Bosch, F. A., \& Volberda, H. W. (2009). Structural differentiation and ambidexterity: The mediating role of integration mechanisms. Organization Science, 20(4), 797-811.

Junni, P., R.M. Sarala, V. Taras, and S.Y. Tarba. 2013. "Organizational ambidexterity and performance: A meta-analysis". The Academy of Management Perspectives 27(4): 299312.

Kammerlander, N., Burger, D., Fust, A., \& Fueglistaller, U. (2015). Exploration and exploitation in established small and medium-sized enterprises: The effect of CEOs' regulatory focus. Journal of Business Venturing, 30(4), 582-602. 
Kapoutsis, I., Papalexandris, A., \& Thanos, I. C. (2016). Hard, soft or ambidextrous? Which influence style promotes managers' task performance and the role of political skill. The International Journal of Human Resource Management, 1-30.

Kauppila, O. P., \& Tempelaar, M. P. (2016). The social-cognitive underpinnings of employees' ambidextrous behaviour and the supportive role of group managers' leadership. Journal of Management Studies, 53(6), 1019-1044.

Kelly, E. L., S.K. Ammons, K. Chermac, and P. Moen. 2010. "Gendered Challenge, gendered Response: Confronting the Ideal Worker Norm in a White-Collar Organization". Gender \& Society, 24 (3): 281-303.

Keogh, B. 2017. Ambulance Response Programme: Letter to Secretary of State. Leeds: NHS England. Available at https://www.england.nhs.uk/wpcontent/uploads/2017/07/ambulance-response-programme-letter.pdf. (accessed 11 July 2018).

Kilroy, S., P.C. Flood, J. Bosak, and D. Chênevert. 2016. "Perceptions of high-involvement work practices and burnout: the mediating role of job demands". Human Resource Management Journal 26(4): 408-424.

King, N., C. Horrocks. 2010. Interviews in Qualitative Research. London: Sage.

King, N. 2004. "Using templates in the thematic analysis of text" In Essential Guide to Qualitative Methods in Organizational Research, edited by C. Cassell, and G. Symonds. , 256-70.

Klein, K.J, J.C. Ziegert, A.P. Knight, and Y. Xiao. 2006. "Dynamic Delegation: Shared, Hierarchical, and Deindividualized Leadership in Extreme Action Teams". Administrative Science Quarterly 51(4): 590-621.

Knies, E., P. Boselie, J. Gould-Williams, and W. Vandenabeele. 2015. "Call for Papers: Special issue of International Journal of Human Resource Management: Strategic human resource management and public sector performance". The International Journal of

Human Resource Management 26(3): 421-424.

Knights, D., and H. Willmott. 1999. Management lives: Power and identity in Work Organizations. London:Sage.

Langley, A., C. Smallman, H. Tsoukas, and A.H. Van de Ven, A. H. 2013. "Process studies of change in organization and management: Unveiling temporality, activity, and flow." Academy of Management Journal 6(1): 1-13.

Lawrence, T. B., R. Suddaby, and B. Leca. 2011. "Institutional Work: Refocusing Institutional Studies of Organization”. Journal of Management Inquiry 20 (1): 52-58.

Le Fevre, M., P. Boxall, and K. Macky. 2015. "Which workers are more vulnerable to work intensification? An analysis of two national surveys". International Journal of Manpower 36(6): 966-983.

Lièvre, P. 2016. "Etat et développement d'un programme de recherché:Management des situations extremes situations." Revue Française de Gestion. 42(257): 79-94.

Lyng, S. 2004. @Edgework and the Risk-Taking Experience” In Edgework: The Sociology of Risk-Taking,edited by S. Lyng. 3-16, Abingdon: Routledge.

Lyng, S. (1990) Edgework: A Social Psychological Analysis of Voluntary Risk-Taking. American Journal of Sociology, 95:4 pp851-886.

Malik, A., Boyle, B., \& Mitchell, R. (2017a). Contextual ambidexterity and innovation in healthcare in India: the role of HRM. Personnel Review, 46(7), 1358-1380.

Malik, A., Sinha, P., Pereira, V., \& Rowley, C. (2017b). Implementing global-local strategies in a post-GFC era: Creating an ambidextrous context through strategic choice and HRM. Journal of Business Research. 
Malik, A., Pereira, V., \& Tarba, S. (2018). The role of HRM practices in product development: Contextual ambidexterity in a US MNC's subsidiary in India. The International Journal of Human Resource Management, 1-29.

Manning, P.K. and J. Van Maanen. 1978. Policing: A View from the Street. New York, NY: Random House.

Maylor, H., and K. Blackmon. 2005. Researching Business and Management. Basingstoke England: Palgrave-Macmillan.

McCann, L., E. Granter, J. Hassard, and P. Hyde. 2015. "You can't do both - something will give": Limitations of the targets culture in managing UK health care workforces." Human Resource Management 54(4): 773-791.

McCann, J., E. Granter, P. Hyde, and J. Hassard. 2013. "Still Blue-Collar after all these Years? An Ethnography of the Professionalization of Emergency Ambulance Work". Journal of Management Studies 50 (5): 750-776.

McCann, L., J. Hassard, and L.L. Morris. 2008. "Normalized Intensity: The New Labour Process of Middle Management". Journal of Management Studies 45 (2): 343-71.

McDonald, P., and P. Thompson. 2016. "Social media (tion) and the reshaping of public/private boundaries in employment relations". International Journal of Management Reviews,18(1): 69-84.

Maguire, B.J., P.F. O’Meara, R.F. Brightwell, B. O’Neill and G.J. Fitzgerald. 2014. "Occupational injury risk among Australian paramedics: an analysis of national data". Medical Journal of Australia 200(8): 477-480.

Mishra, S., D. Goebart, E. Char, P. Dukes, and I. Ahmed. 2010. "Trauma exposure and symptoms of post-traumatic stress disorder in emergency medical services personnel in Hawaii". Emergency Medicine Journal 27: 708-711.

Morri, M. (2017). Inquiry into sexual harassment, bullying and discrimination in state emergency services. The Daily Telegraph. May 11, 2017. Available at: http://www.dailytelegraph.com.au/news/nsw/inquiry-into-sexual-harassment-bullyingand-discrimination-in-state-emergency-services/newsstory/f4eb21e63755f7b98ba3f705abc22423 (accessed on 18 June 2018).

National Audit Office NAO. 2017. NHS Ambulance Services. London: Stationery Office.

National Audit Office NAO. 2015. Financial sustainability of fire and rescue services. HC 491, Session 2015-16. London: Stationery Office.

National Audit Office NAO. 2011. Transforming NHS ambulance services. HC 1086, session 2010-2012. London: Stationery Office.

Neirotti, P. (2018). Work intensification and employee involvement in lean production: new light on a classic dilemma. The International Journal of Human Resource Management, 126.

Newton, A. and G. Harris. 2015. "Leadership and System Thinking in the Modern Ambulance Service" In Ambulance Services: Leadership and Management Perspectives, edited by P. Wankhade and K. Mackway-Jones. 81-94, Springer: New York.

Newton, A., and D. Hodge. 2012. "The ambulance service: the past, present and future." Journal of Paramedic Practice 4 (5): 303-5.

Ng, T.W.H. and D.C. Feldman. 2008. "Long work hours: a social identity perspective on metaanalysis data". Journal of Organizational Behaviour, 29: 853-880.

NHS Staff Survey. 2018. National Briefing: Issues highlighted by the 2017 NHS Staff Survey. March 2018. Available from:

http://www.nhsstaffsurveys.com/Caches/Files/P3088 ST17 National\%20briefing v5.1 L B RC_FR_20180419.pdf (accessed 10 July 2018).

NHS England. 2014. Five year forward view. Leeds: NHS England. 
NHS England. 2013. Transforming Urgent and Emergency Care in England: Urgent and Emergency Care Review, Phase 1 Report, Leeds: NHS England.

NHS Confederation. 2014. Ripping off the sticking plaster: Whole-systems solutions for urgent and emergency care. London: NHS Confederation.

Nosella, A., Cantarello, S., \& Filippini, R. (2012). The intellectual structure of organizational ambidexterity: A bibliographic investigation into the state of the art. Strategic Organization, 10(4), 450-465.

O'Hara, R., M. Johnson, A. N. Siriwardena, A. Weyman, J. Turner, D. Shaw, P. Mortimer, et al. 2015."A Qualitative Study of Systemic Influences on Paramedic Decision Making: Care Transitions and Patient Safety." Journal of Health Services Research \& Policy 20 (1_suppl): 45-53.

Palmer, C. E. 1983. "Trauma Junkies" and Street Work: Occupational Behavior of Paramedics and Emergency Medical Technicians". Journal of Contemporary Ethnography 12 (2): 16283.

Patel, P., J. Messersmith, and D. Lepak. 2013. "Walking the tightrope: An assessment of the relationship between high performance work systems and organizational ambidexterity". Academy of Management Journal, 56(5): 1420-1442.

Piasna, A. 2018. "Scheduled to work hard: The relationship between non-standard working hours and work intensity among European workers (2005-2015)". Human Resource Management Journal. 28(1):167-181.

Polonsky, M. J., and D.S. Waller. 2005. Designing and managing a research project: $A$ business students guide. London: Sage.

Pollitt, C. 2003. The Essential Public Manager, Maidenhead: Open University Press.

Pollitt, C. and G. Bouckaert 2000. Public Management Reform: A Comparative Analysis. Oxford: Oxford University Press.

Pollock, A.C. 2013. "Ambulance services in London and Great Britain from 1860 until today: a glimpse of history gleaned mainly from the pages of contemporary journals". Emergency Medicine Journal, 30: 218-22

Prichard, J., J. Turnbull, S. Halford, and C. Pope. 2014. "Trusting technical change in call centres". Work, Employment and Society 28(5): 808-824.

Raisch, S., Birkinshaw, J., Probst, G., \& Tushman, M. L. (2009). Organizational ambidexterity: Balancing exploitation and exploration for sustained performance. Organization Science, 20(4), 685-695.

Radcliffe, J., and G. Heath. 2009. "Ambulance calls and cancellations: policy and implementation issues". International Journal of Public Sector Management 22 (5): 410422.

Reynolds, T. 2009. Blood, Sweat and Tea: Real-Life Adventures in an Inner-City Ambulance. London: The Friday Project.

Reynolds, T. 2010. More Blood, More Sweat, and Another Cup of Tea. London: The Friday Project.

Schor, J. 2011. True Wealth. London: Penguin.

Scott, W.R. 2008. "Lords of the Dance: Professionals as Institutional Agents". Organization Studies 29(2): 219-38.

Seshadri, S. B., Piderit, S. K., \& Giridharadas, R. (2010). How many minds does a team have? Contextual ambidexterity and goal harmony in healthcare. In Academy of Management Proceedings (Vol. 2010, No. 1, pp. 1-6). Briarcliff Manor, NY 10510: Academy of Management.

Shaw, E. K., J. Howard, E.C. Clark, R.S. Etz, R. Arya, and A.F. Tallia. 2013. "Decision-making processes of patients who use the emergency department for primary care needs". Journal of Health Care for the Poor and Underserved 24(3): 1288-1305.

Silverman, D. 2011. Qualitative Research. London: Sage. 
Siriwardena, A.N., R. Donohoe, J. Stephenson, and P. Phillips. 2010. "Supporting research and development in ambulance services: research for better health care in prehospital settings". Emergency Medicine Journal 27: 324-326.

Smith, E., and T. Umans. 2015. "Organizational Ambidexterity at the Local Government Level: The effects of managerial focus". Public Management Review 17 (6): 812-833.

Smith, C.W. 2004. "Financial Edgework: Trading in market Currents" In Edgework: The Sociology of Risk-Taking, edited by S. Lyng. 187-200, Abingdon: Routledge.

Snooks, H., A. Evans, B. Wells, J. Peconi, M. Thomas, M. Woollard, H. Guly, E. Jenkinson, J. Turner, and C. Hartley-Sharpe. 2009. "What are the highest priorities for research in emergency prehospital care?” Emergency Medicine Journal 26: 549-550.

Sterud, T., E. Hem, B. Lau, and O. Ekeberg. 2011. "A comparison of general and ambulance specific stressors: predictors of job satisfaction and health problems in a nationwide oneyear follow-up study of Norwegian ambulance personnel". Journal of Occupational Medicine and Toxicology 6 (10): 1-9.

Stokes, P., N. Moore, M. Mathews, D. Moss, S. Smith, and Y. Liu. 2015. “The MicroDynamics of Intra-Organizational and Individual Action and their Role in Organizational Ambidexterity." Human Resource Management 54(1): 63-86.

Stokes, P., and P. Harris. 2012. "Micro-moments, choice and responsibility in sustainable organizational change and transformation: the Janus dialectic". Journal of Organizational Change Management 25(4): 595-611.

Sturges, J. and D. Guest. 2006. "Working to live or living to work? Work/life balance early in the career". Human Resource Management Journal 14(4): 5-20.

Tangherlini, T. L. 2000. "Heroes and Lies: Storytelling Tactics among Paramedics". Folklore 111(1): 43-66.

The King's Fund. 2015. Making the difference: diversity and inclusion in the NHS. London: The King's Fund.

Turnball, P., and V. Wass. 2015. "Normalizing extreme work in the police service? Austerity and the inspecting ranks". Organization. 22(4): 512-519.

Turner, J., J. Coster, D. Chambers, et al. 2015. "What evidence is there on the effectiveness of different models of delivering urgent care? A rapid review". Health Services and Delivery Research, 3 (43): 1-133.

Tushman, M. L., and C.A. O’Reilly. 1996. “Ambidextrous organizations: Managing evolutionary and revolutionary change". California Management Review 38(4): 8-30.

van der Ploeg, E. and R.J. Kleber. 2003. "Acute and chronic job stressors among ambulance personnel: predictors of health symptoms". Occupational Environment Medicine 60(Suppl 1): 40-46.

Van Maanen, J. 1988. Tales of the field: On writing ethnography. Chicago, IL: University of Chicago Press.

Van Maanen, J. 2011. "Ethnography as Work: Some Rules of Engagement'. Journal of Management Studies 48(1): 218-234.

Van Maanen, J. 1978. "The Asshole" In Policing: A View from the Street, edited by P.K. Manning and J. Van Maanen, 221-238. New York: Random House.

Van Wart, M. 2014. Dynamics of Leadership in Public Service: Theory and practice. London:Routledge.

Vaze, R. 2018. NHS survey reveals staff are determined to make the best of tough conditions. The Guardian. 9 March 2018. Available from: https://www.theguardian.com/healthcarenetwork/2018/mar/09/nhs-survey-staff-determined-best-tough-conditions (accessed 30 June 2018).

Volery, T., Mueller, S., \& von Siemens, B. (2015). Entrepreneur ambidexterity: A study of entrepreneur behaviours and competencies in growth-oriented small and medium-sized 
enterprises. International Small Business Journal, 33(2), 109-129.

Waddington, P.A.J. 1999. "Police (Canteen) Sub-Culture". British Journal of Criminology, 39(2): 287-309.

Waddington, D. 2004. "Participant observation" In Essential Guide to Qualitative Methods in Organizational Research, edited by C. Cassell and G. Symon. London: Sage.

Wagner, D., M. Heinrichs. and U. Ehlert. 2002. "Prevalence of symptoms of posttraumatic stress disorder in German professional firefighters." American Journal of Psychiatry 155: 1727-32.

Wagner, S., R. Pasca, and J. Fairfax-Croisini. 2016. "Hostility in firefighters: personality and mental health". International Journal of Emergency Services, 5(1): 6-17.

Wankhade, P., G. Heath, and J. Radcliffe. 2018. "Culture change and perpetuation in organisations: evidence from an English ambulance service." Public Management Review 20(6): 934-948.

Wankhade, P. 2018. "The crisis in NHS Ambulance Services in the UK: Let's deal with the 'elephants in the room'!" Ambulance Today 15(1): 13-17.

Wankhade, P. 2016. "Staff perceptions and changing role of pre-hospital profession in the UK ambulance services: an exploratory study". International Journal of Emergency Services 5(2): 126-144.

Wankhade, P., and Mackway-Jones, K. (eds.) 2015. Ambulance Services: Leadership and Management Perspectives. Springer: New York.

Wankhade, P., J. Radcliffe, and G. Heath. 2015. "Organizational and Professional Cultures: An Ambulance Perspective" In Ambulance Services: Leadership and Management Perspectives, edited by P. Wankhade and K. Mackway-Jones, 65-80, Springer: New York.

Wankhade, P., and J. Brinkman. 2014. "The negative consequences of culture change management: evidence from a UK NHS ambulance service". International Journal of Public Sector Management 27(1): 2-25.

Wankhade, P. 2012. "Different Cultures of Management and their Relationships with Organizational Performance: Evidence from the UK Ambulance Service". Public Money \& Management 32 (5): 381-388.

Wankhade, P. and P. Murphy 2012. "Bridging the theory and practice gap in emergency services research: case for a new journal." International Journal of Emergency Services 1 (1): 4-9.

Wankhade, P. 2011. "Performance Measurement and the UK Emergency Ambulance Service: Unintended Consequences of the Ambulance Response Time Targets". International Journal of Public Sector Management 24(5): 382-402.

Wankhade, P. and J. Brinkman. 2011. "Dilemmas of ambulance professionals in attending to an emergency within eight minutes: The ethics of target setting" In From Critique to Action: The Practical Ethics of the Organizational World, edited by D.T.H, Weir and N. Sultan. 106-129, Cambridge Scholars: Newcastle -Upon-Tyre.

Wiesel, F., and S. Modell. 2014. "From new public management to new public governance? Hybridization and implications for public sector consumerism". Financial Accountability \& Management 30(2): 175-205.

Winsor, T.P. 2016. State of Policing: The Annual Assessment of Policing in England and

Wales. Report of Her Majesty's Chief Inspector of Constabulary. London: Stationery

Office.

Yin, R. K.2009. Case study research: Design and methods (4th ed.). London: Sage.

Zhang, L. and J. Seo. 2018. "Held captive in the office: an investigation into long working hours among Korean employees". The International Journal of Human Resource Management. 29(7): 1231-1256. 
Zimmermann, A., Raisch, S., \& Cardinal, L. B. (2018). Managing persistent tensions on the frontline: A configurational perspective on ambidexterity. Journal of Management Studies, 55(5), 739-769. 
Table 1: An ambidextrous conceptual framework of extreme experience in the ambulance service.

\section{The organizational ambidexterity exploitative: explorative boundary}

Nature of the Boundary: individuals and small groups wrestle to negotiate, develop and maintain identity, sense-making and well-being as the ongoing micro-extreme and macro-extreme dynamic unfolds.

\section{Micro-situations}

(i.e. localised spatially and geographically, focused on, and grounded in, individual and small-group experience and exchange - a conversation, an exchange of looks, pressure being exerted.

Micro-extremes often may not initially appear to external observers as extremes however for the individual(s) they are experienced as highly charged and powerful experiences.)

Giving rise to mundane-extreme events and occurrences in the course of daily life (e.g. tensions, bullying, harassment etc).

\section{Exploitative background conditions}

(i.e. comprises routines, quotidian practices.

Micro-extreme instances often occur in seemingly exploitative contexts.)

\begin{tabular}{|c|c|}
\hline \multicolumn{2}{|r|}{$\begin{array}{l}\text { Macro-situations } \\
\text { (i.e. occurring against the backdrop of a major } \\
\text { incident or event - the individual experiences } \\
\text { the event and tries to make sense of the potent } \\
\text { and often traumatic experience e.g. road traffic } \\
\text { accident. } \\
\text { Macro-extremes perhaps constitute a more } \\
\text { common and popular understanding of a } \\
\text { public perception of 'extremes'.) }\end{array}$} \\
\hline 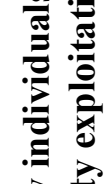 & $\begin{array}{l}\text { Giving rise to periodic and episodic } \\
\text { intense-extreme events (e.g. attendance at } \\
\text { accidents and traumas). }\end{array}$ \\
\hline 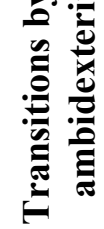 & $\begin{array}{l}\text { Explorative background conditions } \\
\text { (i.e. comprises rapid and stark events and crisis } \\
\text { or radical change. } \\
\text { Macro-extreme instances often occur in } \\
\text { explorative conditions and contexts.) }\end{array}$ \\
\hline
\end{tabular}

Table 2 Respondents in the study

\begin{tabular}{|ll|}
\hline Job description & Quantity \\
Senior board executives & 4 \\
Managerial staff & 7 \\
Frontline paramedic & 3 \\
\hline
\end{tabular}

